\title{
MODALIZAÇÃO COMO RECURSO ENUNCIATIVO: A MARCA DA SUBJETIVIDADE EM TEXTO DISSERTATIVO-ARGUMENTATIVO
}

\author{
Mariana Lima da Silva* \\ Monica Fontenelle Carneiro ${ }^{* *}$
}

RESUMO: Considerando que o recurso da modalização se configura como uma estratégia do sujeito manobrar o texto de acordo com seus interesses, neste artigo, procurou-se analisar sob o viés da Linguística Enunciativa e Textual, o uso dos modalizadores epistêmicos e deônticos em texto dissertativo-argumentativo. No que se refere à fundamentação teórica, recorreu-se as conceitualizações de Authier-Revuz (2004) e Ducrot (1987) e ainda, aos trabalhos de Coracini (1991), Corbari (2016), Nascimento (2010) e Pinto (1994). Como corpus de análise, utilizamo-nos de uma redação nota mil do Exame Nacional do Ensino Médio (ENEM) do ano de 2018. Sobre a abordagem aqui considerada, valemo-nos de pesquisa qualitativa caráter descritivo- interpretativista, pautada na revisão bibliográfica consultada. Como resultado da análise, verificamos a presença das marcas enunciativa de modalização deôntica e epistêmica, ambas remetendo para a construção subjetiva de quem enuncia por meio da argumentação, o que nos permitiu verificar que o uso da modalização como marca enunciativa revela, no texto dissertativo-argumentativo, a atitude do enunciador de chamar atenção, ressaltar argumentos, avaliar informações, ou seja, seu posicionamento.

PALAVRAS-CHAVE: Modalização; Marca enunciativa; Subjetividade; Texto dissertativo-argumentativo.

\section{Introdução}

Os modalizadores são elementos importantes na construção da tessitura textual, bem como na construção do sentido de um texto. A origem das modalidades, conforme aponta Koch (2002) consta desde os estudos da lógica clássica. No que tange o estudo da modalização, esse tem suas bases na lógica da linguagem e na Pragmática, no entanto também é tratado na Linguística Textual e na Análise do Discurso. Assim, tendo em vista que o conceito de modalização permeia os dois últimos quadros teóricos, optaremos por inserir este artigo nos moldes da Linguística Enunciativa e Textual.

No texto dissertativo-argumentativo a presença da modalização é bastante requerida e sinaliza o modo como o sujeito organiza seus argumentos a fim de convencer seu

\footnotetext{
* Mestranda em Letras pela Universidade Federal do Maranhão (Ufma).

** Doutora em Linguística pela Universidade Federal do Ceará (UFC). Professora da Universidade Federal do Maranhão (Ufma).
} 
interlocutor. Diante disso, neste artigo nos propomos analisar o uso dos modalizadores epistêmicos e deônticos em texto dissertativo-argumentativo. Assim, para isso nos valemos da identificação dos modalizadores presentes no texto dissertativo-argumentativo, da descrição do uso dos modalizadores como um recurso em que o locutor se enuncia no discurso a fim de tecer os argumentos de modo a convencer o seu interlocutor. E ainda, nos propomos relacionar o uso da modalização como uma marca enunciativa à noção de subjetividade do sujeito-enunciador.

A presente análise pauta-se no entendimento de que a subjetividade pode ser expressa através da modalização (CORACINI, 1991), que reflete o posicionamento enunciativo do sujeito no nível textual, manobrando seus argumentos por meio da modalidade.

No que concerne o corpus de análise, este é formado por uma redação nota mil do Exame Nacional do Ensino Médio (ENEM) do ano de 2018, retirada do portal do Ministério da Educação. Sobre a abordagem aqui considerada, utilizamo-nos de pesquisa qualitativa caráter descritivo-interpretativista, pautada na revisão bibliográfica consultada.

O presente artigo, como já citado, insere-se dentro dos quadros da Linguística Enunciativa e Textual e justifica-se, por um lado, por proporcionar uma análise enunciativa para além das categorias de pessoa, de tempo e de lugar, proposta por Benveniste (1988). Além disso, se faz necessário uma análise da subjetividade em texto dissertativo-argumentativo, texto caracterizado por exigir objetividade, assim, a modalização traz essa possibilidade de investigação. Por outro lado, propícia a verificação de outros discursos (discurso outro) a partir do qual a modalização possibilita ao sujeito construir seu texto, como base em seus anseios, dispondo-se na superfície do discurso.

E ainda, acreditamos ser importante uma investigação que lance luzes para aspectos envolvendo textos que fazem parte do contexto social no qual nos inserimos, como o caso da redação, bastante presente no contexto de sala de aula e nos principais exames e vestibulares nacionais.

Por fim, estruturamos o artigo do seguinte modo: inicialmente, apresentamos sobre subjetividade, focando nos conceitos de sujeito e enunciado; em seguida, as compreensões sobre modalização e tipos de modalização; posteriormente, apresentamos a metodologia utilizada; em seguida, realizamos a análise e, finalmente, tecemos as considerações finais.

\section{Subjetividade: sujeito e enunciado}

Para falar de modalização torna-se necessário que dediquemos algumas palavras para a noção de sujeito e de enunciado. Assim, no que refere ao conceito de sujeito, ao longo dos 
anos diversas concepções foram apresentadas, inseridas em diferentes abordagens. Dentre essas, a noção de sujeito apresentada por Benveniste (1988) que toma o sujeito como centrado na figura do "eu", segundo o qual seria na linguagem e por meio dela que o homem se assumiria como sujeito. Assim sendo, o sujeito se configuraria, nas palavras do autor, como a colocação do locutor na linguagem, através do seu assumir no discurso na figura do "eu" em contraposição a um "tu” na enunciação.

De maneira contrária ao conceito proposto por Benveniste, que foca na centralidade do “eu”, Bakhtin designa sujeito como produto da relação do 'eu' com o outro, ou seja, o sujeito seria constituído a partir das relações sociais que estabelece com os outros. Assim, "Bakhtin não confere ao eu um lugar central, mas coloca o outro como eixo de todo seu trabalho", sem, contudo, o aspecto social abalar o individual, conforme aponta Freitas et. al. (2015, p.52). Mediante essa concepção, a noção de sujeito, portanto, se apresenta fincada nas relações sociais em que o outro se assume como a base para esse sujeito se constituir.

Já na perspectiva de Authier-Revuz (2004), dialogando com definição proposta por Bakhtin, a noção de sujeito se dá como atravessado constitutivamente por outro, de modo específico pelas palavras do outro. No entendimento da autora, o sujeito é, então, dividido e descentrado, cujo discurso é fundamentalmente heterogêneo. Dividido porque o mesmo não é uma entidade homogênea, mas é resultado não apenas da relação com o outro, mas também pelo inconsciente (referente à vontade, ao desejo) e descentrado por não existir centro para sujeito apenas dentro de uma ilusão criada por ele.

Para além do conceito de sujeito, mas também relacionado à modalidade o conceito de enunciado se faz necessário destacar. Authier (2004), nessa linha da heterogeneidade, considera enunciado como o lugar em que manifesta a heterogeneidade, podendo ser de dois tipos, os que revelam a heterogeneidade através de sinais explícitos, como as aspas e itálico; e os que revelam a heterogeneidade de modo implícito sem o uso de marcas linguísticas explícitas, a exemplo da ironia e do discurso indireto livre.

Nesta acepção, então, o enunciado não é algo detido no individual de um "eu", mas sim um ato heterogêneo ligado à enunciação em que se inscreve o discurso outro.

Ducrot (1987, p. 164), por sua vez, o define como uma "manifestação particular, como a ocorrência bic et nunc de uma frase", ou seja, o enunciado está no nível do particular porque ao passo que uma mesma frase é pronunciada por diferentes pessoas, diferentes enunciados são criados. Para o autor, o enunciado fornece as fontes da enunciação, que estão inseridas no seu sentido. 
Dessa forma, com base nessas definições de sujeito e de enunciado, especificamente, as conceitualizações de sujeito e enunciado defendido por Authier (2004), podemos dizer que a modalidade é uma estratégia argumentativa utilizada pelo sujeito dentro do enunciado. Assim, circunscrevemos a definição de subjetividade como àquela em que por meio da modalidade o sujeito organiza seus argumentos e exprime seu ponto de vista. Nessa perspectiva, acreditamos que essa subjetividade se faz existir mesmo em texto dissertativo-argumentativo cuja característica é a objetividade.

\section{Modalização}

O recurso da modalização configura-se como uma estratégia do sujeito manobrar seu texto de acordo com seus interesses, ou seja, através dele se inserir no enunciado. Nesse sentido, o conceito de modalização, conforme aponta Pinto (1994), diz respeito ao modo de qualificação que o sujeito faz a respeito do significado, avaliando o conteúdo expresso. Dito de outro modo, a modalização pode ser compreendida como "a expressão da subjetividade de um enunciador que assume com maior ou menor força o que enuncia, ora comprometendo-se, ora afastando-se, seguindo normas determinadas pela comunidade em que se insere" Coracini (1991, p. 113). Ora, torna-se nítido que a autora compreende que a postura assumida pelo sujeito pautada pela escolha dos modalizadores revela sua subjetividade. Em vista disso, e considerando os propósitos do presente artigo, é que o conceito apresentado por Coracini (1991) se faz relevante para a análise que aqui nos propomos.

Nas discussões da autora sobre o discurso subjetivo da ciência, Coracini (1991) pontua que todo enunciado se faz presente dentro de um "quadro enunciativo do qual é preciso partir se deseja descrever seu funcionamento alético" (CORACINI, 1991, p.120). Assim, sob o ponto de vista da autora, a modalidade, assumida como um envolvimento do próprio sujeito-enunciador, acontece antes mesmo da própria construção do texto, constituindo-se, assim, a modalização implícita, que revela o caráter de anterioridade da enunciação frente às unidades linguísticas. Dando seguimento ao texto, a autora defende que a modalidade pode revelar a opinião do enunciador, podendo se apresentar tanto implícita no nível do texto, como também por meio de marcação modal. E ainda,

5) as 'marcas' modais em si não determinam a priori o ponto de vista do sujeitoenunciador nem as interpretações possíveis: sua presença ou ausência aponta apenas para uma possível interpretação do texto;

6) as modalidades constituem verdadeiras estratégias retórico-argumentativas, na medida em que pressupõem uma intencionalidade discursiva, não podendo ser isoladas do ato de fala em que estão inseridas. (CORACINI, 1991, p. 120) 
É verificável, com vista nos argumentos da autora, a existência de dois tipos de modalidade, a explícita e a implícita. Desse modo, na visão da autora, as modalidades do discurso científico consistem num desejo do enunciador de passar objetividade, no entanto, essa subjetividade, ainda se faz presente através da avaliação, do julgamento e do destaque a fim de chamar a atenção de quem o ler.

Ainda sob o conceito de modalização, Pinto (1994), ao apresentar o conceito de modalização da enunciação, afirma que esta visa atender um propósito comunicacional, podendo ser "marcada diretamente no interior de um enunciado", através da utilização "de determinados itens lexicais ou construções morfossintáticas, ou ser inferida indiretamente a partir do contraste entre o enunciado e a situação e/ou cotexto" (PINTO, 1994, p. 81).

Observando a colocação do autor, podemos perceber que o mesmo parece corroborar com a argumentação de Coracini (1991) sobre a existência de modalidades explícitas e implícitas. Assim, sobre a modalização do enunciado Pinto (1994) discorre sobre os tipos de modalização. A esse respeito, apresentamos no seguinte item alguns apontamentos.

\section{Tipos de modalização}

Falar sobre modalização do enunciado requer relacionar à importância que o sujeito dá ao que ele circunscreve no enunciado. Tal modalização pode ser representada de diferentes tipos, a saber: modalidades ônticas, modalidades aléticas, modalidades epistêmicas e modalidades axiológicas. Tomando o trabalho de Pinto (1994) apresentamos brevemente o resumo dos apontamentos do autor sobre cada tipo de modalidades. Segundo Pinto (1994, p. 102), modalidades ônticas podem ser expressas pelos adjetivos factuais ou reais, contrafactuais ou irreais, hipotéticos ou aparentes e não factuais ou não reais e "seus derivados nominais, verbais ou adverbiais, ou por sinônimos".

Outros tipos de modalidades são as aléticas, o autor aponta que se revelam em enunciados em que sua construção seja fazer uma declaração e podem ser expressas por meio dos adjetivos necessário, impossível, possível e contingente, bem como de seus derivados verbais, adverbiais e nominais, além dos sinônimos.

Já as modalidades epistêmicas dizem respeito, conforme inscreve Pinto (1994), às marcações dos adjetivos certo (crer ser), excluído (crer não ser), plausível (não crer não ser) e contestável (não crer ser) e seus verbos, substantivos e advérbios que deles se originam e ainda por seus sinônimos e outras construções. As modalidades deônticas, em contrapartida, podem ser marcadas pelos adjetivos obrigatório, proibido, permitido e facultativo, e ainda, por seus derivados e sinônimos. 
$\mathrm{E}$, finalmente, no que se referem às modalidades axiológicas, estas dizem respeito aos juízos intelectuais e afetivos criados pelos enunciados, podendo ser expressas por meio de adjetivos, verbos, advérbios e substantivos correspondentes.

Em vista dessa classificação, nesta análise, levaremos em conta apenas as modalidades epistêmicas e deônticas, em virtude, principalmente de serem as mais frequentes no corpus em análise, especificamente as marcas deônticas de obrigatoriedade e sugestão. Assim, sob estas marcas enunciativas faremos algumas proposições:

a) Conforme demarca Corbari (2016) a modalização deôntica está inserida âmbito do dever referente ao aspecto da conduta e,

b) A modalização epistêmica situa-se no âmbito da crença, referindo-se ao que o enunciador do texto avalia com base em seu conhecimento sobre a temática abordada. (CORBARI, 2016).

Complementando,

i) Ao considerar a argumentação como lugar de negociação dos interlocutores, parece ser inevitável a existência de certa subjetividade do enunciador, uma vez que este tem por objetivo convencer o outro;

ii) A modalização sendo uma marca enunciativa revela no texto dissertativo-argumentativo a atitude do enunciador de chamar atenção, ressaltar argumentos, avaliar informações, ou seja, seu posicionamento;

iii) Ao recorrer ao uso dos modalizadores o enunciador visa, ainda, atender as exigências do gênero textual em questão.

\section{Metodologia}

Inserindo-nos na perspectiva da Linguística Enunciativa e Textual, considerando ser "no ato de enunciação, quando apropriada língua, que o locutor faz a passagem a sujeito e implanta o outro diante de si, atualizando a comunicação intersubjetiva" (SILVA, 2018, p. 425-426), aos propósitos deste artigo, o corpus de análise é formado por uma redação nota mil do Exame Nacional do Ensino Médio (ENEM) do ano de 2018, retirado do site do portal do Ministério da Educação, cuja temática foi "Manipulação do comportamento do usuário pelo controle de dados na Internet".

Sobre a abordagem aqui considerada, utilizamo-nos de pesquisa qualitativa de caráter descritivo-interpretativista, pautada na revisão bibliográfica consultada. Assim, conforme aponta Brasileiro (2013, p. 49), a pesquisa qualitativa "é a aquela que se ocupa da interpretação dos fenômenos e da atribuição de significados no decorrer da pesquisa, não se detendo de técnicas estatísticas." 
No que se refere ao caráter descritivo-interpretativista, valemo-nos do entendimento de que por meio desta análise buscamos expor e caracterizar o fenômeno da modalização, ressaltando seu caráter enunciativo de subjetividade em texto dissertativo-argumentativo.

A escolha da redação para a análise aqui proposta não se pautou em escolha seletiva, sendo escolhida de modo aleatório entre tantas outras redações nota mil do ano de 2018. Nesta análise que nos propomos realizar, selecionamos apenas os trechos da redação em houve a identificação de modalizadores epistêmicos e deônticos.

\section{Modalização como recurso enunciativo: a marca da subjetividade em texto disserta- tivo-argumentativo}

No texto dissertativo-argumentativo tem-se a argumentação como constituinte base, sendo sua presença organizada seguindo a estrutura introdução (apresentação de uma tese), desenvolvimento, parte em que são expostos os argumentos, e conclusão. Sob esses aspectos é que constitui a proposta do ENEM, levando em conta para correção das redações certas competências que o candidato deve atingir.

A argumentação, nessa perspectiva, pode ser "tomada de posição contra outra posição", configurando-se "a natureza dialógica do discurso.” (FIORIN, 2016, p.29). Tendo como foco a modalização como recurso enunciador em que inscreve a subjetividade do enunciador, apresentamos como isso se dá por intermédios dos modalizadores epistêmicos e deônticos na redação do ENEM escolhida para esta análise.

A Redação aqui analisada foi a do candidato Mattheus Martins Wengenroth Cardoso, do ano 2018, cuja temática foi "Manipulação do comportamento do usuário pelo controle de dados na Internet".

O advento da internet possibilitou um avanço das formas de comunicação e permitiu um maior acesso à informação. No entanto, a venda de dados particulares de usuários se mostra um grande problema. Apesar dos esforços para coibir essa prática, o combate à manipulação de usuários por meio de controle de dados representa um enorme desafio. Pode-se dizer, então, que a negligência por parte do governo e a forte mentalidade individualista dos empresários são os principais responsáveis pelo quadro.

Em primeiro lugar, deve-se ressaltar a ausência de medidas governamentais para combater a venda de dados pessoais e a manipulação do comportamento nas redes. Segundo o pensador Thomas Hobbes, o Estado é responsável por garantir o bemestar da população, entretanto, isso não ocorre no Brasil. Devido à falta de atuação das autoridades, grandes empresas sentem-se livres para invadir a privacidade dos usuários e vender informações pessoais para empresários que desejam direcionar suas propagandas. Dessa forma, a opinião dos consumidores é influenciada, e o direito à liberdade de escolha é ameaçado.

Outrossim, a busca pelo ganho pessoal acima de tudo também pode ser apontado como responsável pelo problema. De acordo com o pensamento marxista, priorizar o bem pessoal em detrimento do coletivo gera inúmeras dificuldades para a sociedade. 


\begin{abstract}
Ao vender dados particulares e manipular o comportamento de usuários, empresas invadem a privacidade dos indivíduos e ferem importantes direitos da população em nome de interesse individuais. Desse modo, a união da sociedade é essencial para garantir o bem-estar coletivo e combater o controle de dados e a manipulação do comportamento no meio digital.

Infere-se, portanto, que assegurar a privacidade e a liberdade de escolha na internet é um grande desafio no Brasil. Sendo assim, o Governo Federal, como instância máxima de administração executiva, deve atuar em favor da população, através da criação de leis que proíbam a venda de dados dos usuários, a fim de que empresas que utilizam essa prática sejam punidas e a privacidade dos usuários seja assegurada. Além disso, a sociedade, como conjunto de indivíduos que compartilham valores culturais e sociais, deve atuar em conjunto e combater a manipulação e o controle de informações, por meio de boicotes e campanhas de mobilização, para que os empresários sintam-se pressionados pela população e sejam obrigados a abandonar a prática.

Afinal, conforme afirmou Rousseau: "a vontade geral deve emanar de todos para ser aplicada a todos".
\end{abstract}

Logo de início no texto, o enunciador apresenta, antes de apresentar sua tese, duas marcações de modalização epistêmica, a primeira possibilitou um avanço e a segunda permitiu. Ambos inseridos no campo da avaliação do contexto atual realizada pelo enunciador, sob a qual a temática do ENEM está incluída. Ainda, no mesmo parágrafo o produtor da redação ao introduzir um ouro ponto de visa fazer uso de outro modalizador epistêmico se mostra, também de avaliação.

No entanto, para inserir sua tese o enunciador recorre ao uso da modalização deôntica de permissividade, revelado pelo pode-se dizer, que ao mesmo tempo em que apresenta o posicionamento do sujeito enunciador, chama a atenção do interlocutor, conforme explícita Coracini (1991, p.129), há uso de verbos no imperativo com "formas impessoais que implicam a referência ao outro". Como podemos ver abaixo em [A]:

[A] $\mathrm{O}$ advento da internet possibilitou um avanço das formas de comunicação e permitiu um maior acesso à informação. No entanto, a venda de dados particulares de usuários se mostra um grande problema. Apesar dos esforços para coibir essa prática, o combate à manipulação de usuários por meio de controle de dados representa um enorme desafio. Pode-se dizer, então, que a negligência por parte deo governo e a forte mentalidade individualista dos empresários são os principais responsáveis pelo quadro.

Há, com vista nas marcações acima a visualização de verbos no pretérito perfeito ligada a avaliação que o sujeito realiza e o uso de verbo no imperativo para dá destaque ao que defende, ou seja, se verifica, já nesse trecho, a presença de um sujeito que se enuncia subjetivamente seu discurso, por meio dos modalizadores, a fim de prender e convencer seu interlocutor, corroborando para os propósitos do tipo textual, que é o de persuadir.

Em outro parágrafo temos: 
[B] Em primeiro lugar, deve-se ressaltar a ausência de medidas governamentais para combater a venda de dados pessoais e a manipulação do comportamento nas redes. Segundo o pensador Thomas Hobbes, o Estado é responsável por garantir o bem-estar da população, entretanto, isso não ocorre no Brasil.

Nesse trecho o sujeito, por meio da modalização deôntica de obrigatoriedade [deve-se], dirige-se ao seu interlocutor ao passo que também manifesta seu posicionamento, há, nesse sentido, conforme aponta Nascimento (2010, p. 38) o uso de modalização "Inclusiva ou universal", revelada a partir do uso modalizador de caráter deôntico, utilizado "não só para o interlocutor, mas inclui o próprio locutor ou outros locutores ou agentes discursivos". Ora, parece nítido, ainda o uso da modalização em [B] circunscrita no nível da necessidade, em que tendo o sujeito-enunciador tem a pretensão de construir a argumentação persuasiva ele se coloca como um avaliador no domínio obrigação.

Cabe ressaltar, com pauta em Corbari e Bidarra (2007), a existência de dever epistêmico e dever deôntico, no entanto, a diferenciação entre ambos dependerá do contexto que se inscreve. Assim, no trecho [B] do contexto vê-se emanar o sentido deôntico do verbo dever, marcado pela impessoalidade e pelo modo imperativo.

De modo semelhante ao trecho [A] o parágrafo seguinte apresenta uma colocação do sujeito enunciador através da marcação deôntica de permissividade, através da qual o sujeito tanto chama a atenção como faz uma recomendação ao seu interlocutor. Vejamos:

[C] Outrossim, a busca pelo ganho pessoal acima de tudo também pode ser apontado como responsável pelo problema. De acordo com o pensamento marxista, priorizar o bem pessoal em detrimento do coletivo gera inúmeras dificuldades para a sociedade. Ao vender dados particulares e manipular o comportamento de usuários, empresas invadem a privacidade dos indivíduos e ferem importantes direitos da população em nome de interesse individuais. Desse modo, a união da sociedade é essencial para garantir o bem-estar coletivo e combater o controle de dados e a manipulação do comportamento no meio digital.

Nota-se que através do uso do modalizador pode ser o produtor do texto apresenta outro argumento para a defesa de sua tese, há pelo uso dessa modalização uma marca de possibilidade que, tal como aponta Nascimento (2010, p. 34), "recai sobre o conteúdo da proposição uma possibilidade, que também é dada diretamente ao interlocutor sob a forma de uma permissão". Convém acrescentar que o uso do pode ser insere o interlocutor no nível de escolha, o fazendo inferir que existam outras causas para o problema da manipulação da população pelo uso da internet. Assim, podemos verificar o próprio posicionamento do sujeito-enunciador, por meio da escolha dos argumentos, do que considera mais relevante, explicitado pela modalização usada, e que também pode ser visualizada pelo uso do é essencial. 
Dando continuidade à análise, podemos novamente verificar a avaliação e, especificamente o entendimento do sujeito marcado no parágrafo [D] que segue, vejamos:

[D] Infere-se, portanto, que assegurar a privacidade e a liberdade de escolha na internet é um grande desafio no Brasil. Sendo assim, o Governo Federal, como instância máxima de administração executiva, deve atuar em favor da população, através da criação de leis que proíbam a venda de dados dos usuários, a fim de que empresas que utilizam essa prática sejam punidas e a privacidade dos usuários seja assegurada. Além disso, a sociedade, como conjunto de indivíduos que compartilham valores culturais e sociais, deve atuar em conjunto e combater a manipulação e o controle de informações, por meio de boicotes e campanhas de mobilização, para que os empresários sintam-se pressionados pela população e sejam obrigados a abandonar a prática.

O uso da modalização infere-se configura na tessitura textual o fechamento nas argumentações do sujeito- enunciador, que pode ser vista como o resultado das asserções por ele apresentada ao longo do texto, vemos, portanto, mais uma vez sua avaliação e seu posicionamento. Em seguida, vemos mais uma vez a utilização de modalizadores deônticos de obrigação explícita pelo uso do verbo dever (deve atuar). Desse modo, sendo o trecho [D] o parágrafo final do texto, justamente a parte que cabe ao enunciador apresentar uma proposta de intervenção, o uso do verbo no imperativo marca, além do posicionamento do enunciador, uma orientação, de modo a agir sobre seu interlocutor.

A presença majoritária de modalizadores deônticos na redação parece lançar luzes para o objetivo do enunciador de levar seu interlocutor a seguir seu ponto de vista, a se convencer por meio das asserções que se apresenta visível, quase sempre, pelo uso de verbos no imperativo. Além disso, os modalizadores encontrados marcam no enunciado que se inserem diferentes modalizações, que ora se assemelham e ora assumem outro sentido. O que fica claro, no entanto, por exemplo, em [A] e [B] é como se constrói a argumentação ao longo do texto, fincada inicialmente na modalização epistêmica, sob o qual o sujeito-enunciador avalia o tema e o cenário em que insere, a partir do qual pauta seus argumentos por meio de modalização deôntica até o final do texto.

Vale, ainda, ressaltar que ao observar o uso da modalização no texto dissertativo-argumentativo pode-se verificar a realização das proposições elencados por Pinto (1994, p. 81) que são a projeção de um "tipo de interação que deseja estabelecer com o receptor e, por seu intermédio, sobre o mundo"; as revelações públicas das "posições sobre os estados de coisas descritos em seus enunciados, relativamente a critérios de verdade e de valor" e a criação de "sequências de enunciados encadeados (textos) adaptados aos objetivos" de interação e posicionamento do enunciador. 
Nesse sentido, parece ficar claro o próprio caráter da tipologia textual dissertaçãoargumentativa, que prima pela imparcialidade e objetividade do sujeito-enunciador, no entanto, a marcação epistêmica e deôntica revelam a subjetividade, mesmo o autor se valendo de verbos na $3^{a}$ pessoa, pois através desses recursos modais, este avalia, chama a atenção do interlocutor, se posiciona, sugere e recomenda.

\section{Considerações finais}

Neste artigo nos propomos analisar o uso dos modalizadores epistêmicos e deônticos em texto dissertativo-argumentativo. Assim, para isso nos valemos da identificação dos modalizadores presentes no texto dissertativo-argumentativo, da descrição do uso dos modalizadores como um recurso em que o locutor se enuncia no discurso a fim de tecer os argumentos de modo a convencer o seu interlocutor. E ainda, nos propomos a relacionar o uso da modalização como uma marca enunciativa da subjetividade do sujeito-enunciador.

$\mathrm{Na}$ análise que aqui nos detivemos pudemos verificar que a modalização deôntica é uma estratégia de argumentação na qual se inscreve a subjetividade do sujeito- enunciador. Nos trechos da redação aqui levados em consideração em nossa análise, verificamos as marcas enunciativa de modalização deôntica e epistêmica, nas quais encontramos as seguintes modalizações deônticas - de permissividade pode-se dižer, pode ser, infere-se, de obrigatoriedade deve-se, deve atuar, e modalização epistêmica, baseada na crença e na avaliação que o sujeitoenunciador realiza, visualizada em possibilitou, permitiu e se mostra, ambas remetendo para a construção subjetiva de quem enuncia por meio da argumentação.

Assim, com vista nas exposições aqui realizamos podemos destacar que:

a) A modalização assume um caráter de inserção argumentativa;

b) No nível textual a modalização simboliza a presença subjetividade do enunciador mesmo em texto dissertativo-argumentativo;

c) Os modalizadores deônticos podem assumir diferentes nuances, como e possibilidade, obrigação e necessidade, ancorada na argumentação e ponto de vista do sujeito-enunciador;

d) Ao se utilizar de modalizadores epistêmicos o sujeito- enunciador realiza uma avaliação sobre a temática abordada e nela pauta seus argumentos e;

e) A modalização representa uma análise enunciativa para além das categorias de pessoa, tempo e lugar proposta de Benveniste (1998). 
Dessa forma, verificamos que o uso da modalização se constitui como uma marca enunciativa que revela no texto dissertativo-argumentativo a atitude do enunciador de chamar atenção, ressaltar argumentos, avaliar informações, ou seja, seu posicionamento.

\title{
MODALIZATION AS ENUNCIATIVE RESOURCE: THE MARK OF SUBJECTIVITY IN DISSERTATION-ARGUMENTATIVE TEXT
}

\begin{abstract}
Considering that the resource of modalization is configured as a strategy of the subject to maneuver the text according to his interests, in this article, we tried to analyze under the bias of Enunciative and Textual Linguistics, the use of epistemic and deontic modalizers in dissertation-argumentative text. With regard to theoretical foundation, we used the conceptualizations of Authier-Revuz (2004) and Ducrot (1987) and also, the works of Coracini (1991), Corbari (2016), Nascimento (2010) and Pinto (1994). As a corpus of analysis, we used a 1,000 tha note essay of the National High School Exam (ENEM) of 2018. On the approach considered here, we use qualitative research descriptive-interpretative character, based on the literature review consulted. As a result of the analysis, we verified the presence of enunciative marks of deontic and epistemic modalization, both referring to the subjective construction of those who enunciate through argumentation, which allowed us to verify that the use of modalization as an enunciative mark reveals, in the dissertation-argumentative text, the attitude of the enunciator to draw attention, to highlight arguments, to evaluate information, that is, its position.
\end{abstract}

KEYWORDS: Modalization; Enunciative mark; Subjectivity; Dissertation-argumentative text.

\section{REFERÊNCIAS}

AUTHIER-REVUZ, J. Palavras mantidas a distância. In: AUTHIER-REVUZ, J. Entre a transparência e a opacidade: um estudo enunciativo do sentido. Tradução de Heloisa Monteiro Rosário. Porto Alegre, RS: EDIPUCRS, 1980: 2004, p. 217- 37

BENVENISTE, E. Da subjetividade na linguagem. In: BENVENISTE, E. Problemas de linguística geral, 2 ed. Campinas: Editora da Unicamp, Pontes, 1998, p.284-293.

BRASILEIRO, Ada Magaly Matias. Manual de produção de textos acadêmicos e cientifícos. São Paulo: Atlas, 2013.

CORACINI, Maria José Rodrigues Faria. Um fazer persuasivo: o discurso subjetivo da ciência. -1. Ed. São Paulo: Educ: Campinas, SP: Pontes, 1991. 210p.

CORBARI, Alcione Tereza. Modalizadores: a negociação em artigo de opinião. Linguagem em (Dis)curso - LemD, Tubarão, SC, v. 16, n. 1, p. 117-131, jan./abr. 2016.

BIDARRA, Jorge. O modal dever epistêmico e deôntico um problema de processamento lexical. Ciências \& Cognição. Vol. 11, 120-131, 2007.

DUCROT, Oswald. O dizer e o dito. Revisão técnica da tradução Eduardo Guimarães. Campinas, SP: Pontes, 1987.

FIORIN, José Luíz. Argumentação. -1ªed., 2ª reimpressão. -São Paulo: Contexto, 2016.

FREITAS, Maria Teresa de Assunção; BERNARDES, Alessandra Sexto; PEREIRA, Ana Paula Marques Sampaio; PEREIRA, Maria Leopoldina. O sujeito nos textos de Vigotski e do Círculo de Bakhtin: implicações para a prática da pesquisa em educação. Revista de Psicologia, v. 27, n. 1, p. 50-55, jan.-abr. 2015.

KOCH, Ingedore G. V. A inter-relação pela linguagem. 9 ed. -São Paulo: Contexto, 2002. 
PINTO, Milton José. As marcas linguísticas da enunciação: esboço de uma gramática enunciativa do português. Rio de Janeiro: Numem Ed., 1994. 163p.

NASCIMENTO, Erivaldo Pereira do A. Modalização deôntica e suas peculiaridades semântico-pragmáticas. Fórum Lingüístico, Florianópolis, v.7, n.1 (30-45), jan-jun, 2010.

Redação de Matheus Martins Wengenroth Cardoso. Disponível em: http://portal.mec.gov.br/images/stories/noticias/2019/outubro/24.10.2019redacaolink2.pdf. Acesso em: 09 de jan. de 2020.

SILVA, Carmem Luci da Costa. O estudo do texto em uma perspectiva enunciativa de linguagem. Revista D.E.L.T.A., 34.1, 2018 (419-433)

Recebido em: 31/03/2021.

Aprovado em: 04/06/2021. 